九州大学学術情報リポジトリ

Kyushu University Institutional Repository

\title{
Development of Automatic System for Monitoring and Removing of Burr in Side Milling Process of Wood and Wood-based Materials
}

\section{Ouchi, Takeshi}

Department of Technology, Fukuoka University of Eduation

Lin, Han Chien

Department of Forest Products Science, College of Agriculture, National Chiayi University

Fuj imoto, Noboru

Department of Forest and Forest Products Sciences, Fuculty of Agriculture, Kyushu Unviversity

Murase, Yasuhide

Department of Forest and Forest Products Sciences, Fuculty of Agriculture, Kyushu Unviversity

https://doi.org/10.5109/10078

出版情報: 九州大学大学院農学研究院紀要. 53 (1)，pp.101-105，2008-02-28. Faculty of Agriculture, Kyushu University

バージョン :

権利関係 : 


\title{
Development of Automatic System for Monitoring and Removing of Burr in Side Milling Process of Wood and Wood-based Materials
}

\author{
Takeshi OHUCHI*1, Han Chien LIN ${ }^{2}$, Noboru FUJIMOTO ${ }^{3}$ \\ and Yasuhide MURASE ${ }^{3}$
}

\author{
Laboratory of Wood Material Technology, Division of Biomaterial Science, Department of Forest and \\ Forest Products Sciences, Faculty of Agriculture, Kyushu University, \\ Fukuoka 812-8581, Japan \\ (Received November 7, 2007 and accepted November 30, 2007)
}

\begin{abstract}
Computerized numerically controlled (CNC) routers have been used under hard processing conditions with the aim of raising productivity. Therefore, tool wear progresses rapidly, and burr formation occurs on the surface of wood and wood-based materials frequently. Because this burr formation greatly influences product quality and productivity, the development of a system that can monitor it automatically is needed.

In this study, to monitor the burr formed because of tool wear, a charge-coupled device (CCD) vision sensor with high reliability in monitoring was installed in a CNC router, and a system for monitoring the burr formation in side milling and for removing it automatically was developed. In addition, verification experiments of this system were carried out. The main results obtained are as follow:

The side milling system for monitoring burr formation was composed of a CCD vision sensor, a personal computer (PC) for CNC router control, and a monitoring PC to control other devices and collect sampling data for the burr formation. From the result of our verification experiment, it was found that this system could measure the area of the burr formed in side milling and remove it automatically.
\end{abstract}

\section{INTRODUCTION}

Recently, CNC routers have become especially popular in furniture manufacturing, and have been used for the grooving, side milling, and patterning of furniture materials. In these manufacturing processes, a CNC router has been used under hard processing conditions with the aim of raising productivity. Thus, tool wear progresses rapidly, and burr formation on the surface of wood and wood-based materials, as well as chipping of the bit, occur frequently, greatly influencing productivity and product quality. Therefore, the development of a system that can monitor both tool wear and burr formation automatically is needed.

In order to monitor the cutting edge profile of the router bit easily and automatically under processing, the authors installed a laser measuring instrument in a CNC router, and constructed a cutting edge profile measuring system (Ohuchi and Murase 2002b, 2005). The system was composed of a laser measuring instrument, a personal computer (PC) for CNC router control, and a monitoring PC for the control of other devices and the collection of sampling data.

In addition, an adaptive control processing system not only to improve the machining accuracy, which deteriorates with increasing tool wear, but also to control the burr formation that occurs in grooving was constructed

\footnotetext{
Laboratory of Woodworking, Department of Technology, Fukuoka University of Education, Japan

2 Department of Forest Products Science, College of Agriculture, National Chiayi University, Chiayi, Taiwan, ROC

3 Laboratory of Wood Material Technology, Division of Biomaterial Science, Department of Forest and Forest Products Sciences, Faculty of Agriculture, Kyushu University, Japan

* Corresponding author (E-mail: tohuchi@fukuoka-edu.ac.jp)
}

(Ohuchi and Murase 2006). That is, the design was based on experimental data on both the machining accuracy for grooving and side-milling of grooves and the effect of tool wear on burr formation obtained in previous studies (Ohuchi and Murase 2001a, 2001b, 2002a). Thus, a system that automatically optimizes the processing condition for grooving corresponding to the expected progression of tool wear was developed.

However, for the monitoring method of the above-mentioned studies, it was necessary to experiment on various materials to optimize the processing condition. Moreover, its reliability in monitoring burr formation was not sufficient because this method does not perform direct monitoring. Therefore, it was necessary to devise a new sensor that could directly monitor the burr formation.

In this study, to directly monitor burrs formed because of tool wear, a charge-coupled device (CCD) vision sensor with high reliability in monitoring was installed in a CNC router, and a system for monitoring the burr formation in side milling and removing it automatically was developed. Verification experiments of this system were then carried out.

\section{SIDE MILLING SYSTEM}

\section{Outline of system}

Figure 1 shows a schematic diagram of the system for automatically measuring burr formation. This system was composed of a picture processing device, a PC for the $\mathrm{CNC}$ router control, and a monitoring $\mathrm{PC}$ which controls other devices and collects sampling data. The image-processing device was composed of a CCD vision sensor and controller, and the CCD vision sensor was set at the spindle flame of a CNC router as shown in Fig. 1.

A flow-chart of the measurement process in this 


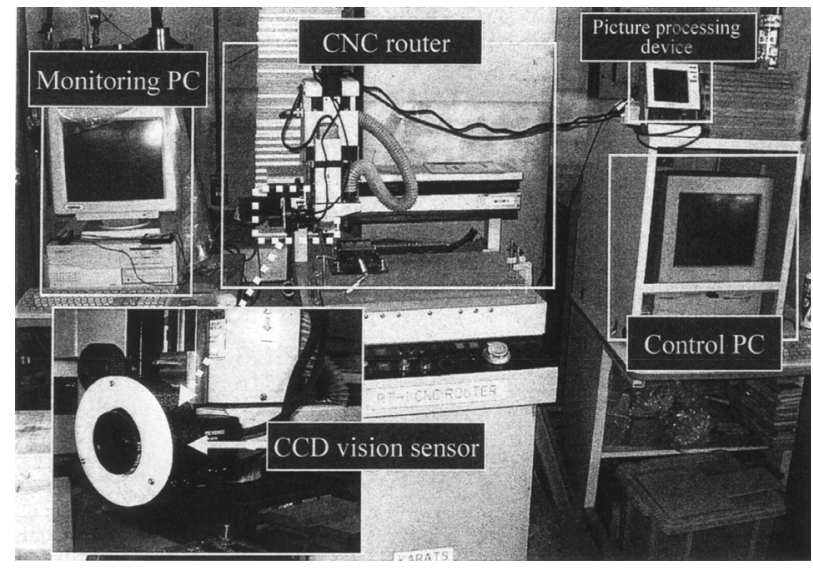

Fig. 1. Schematic diagram of the system for automatically measuring burr formation

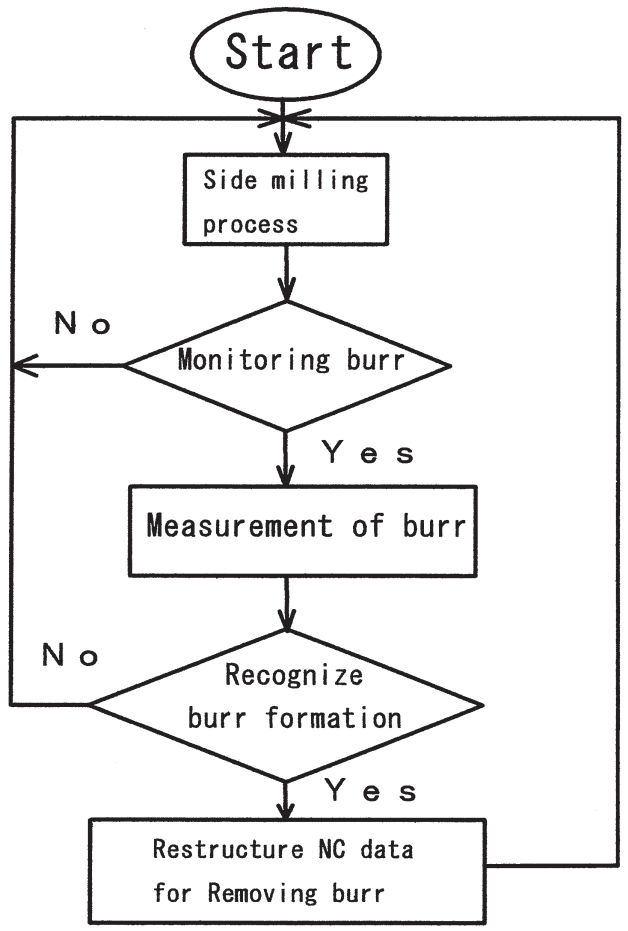

Fig. 2. A flow-chart of the measurement process

system is shown in Figure 2. As the first step of measurement procedure, the monitoring $\mathrm{PC}$ transmits the NC data for side milling to the control $\mathrm{PC}$, and side milling is performed. As a means to monitor automatically whether a burr has been formed or not, a method to check for burr formation when the process reached the number of parts or the processing time established beforehand was devised. That is, the monitoring PC transmits the NC data for the movement of the CCD vision sensor to the control PC when the process reaches the number of parts or processing time experimentally determined to make burrs more likely. Then, the CCD vision sensor that is set at the spindle frame moves to the measurement position at a distance of $240 \mathrm{~mm}$ from the side surface of material. Here, the CCD vision sensor measures the burr area, and the controller outputs this obtained value to the monitoring $\mathrm{PC}$. The monitor PC recognizes the burr formation when the burr area exceeds the threshold, and the NC data that adds the process of removing burr is restructured. The monitor $\mathrm{PC}$ transmits this new NC data to the control PC, and the system returns to the process of side milling.

\section{Measurement method of burr area}

After side milling has been performed for a long time, tool wear progresses and burrs are formed on the surface of the material. The CCD vision sensor moves to the measurement position when the process of side milling reaches the pre-established number of parts or processing time, and the burr formed on the surface of material enters into the measurement area of the controller. The image of the material with burr formation is input to the controller and the color information in the part with the burr is analyzed as shown in Fig. 3. When the burr in this area is recognized as the color of a burr as analyzed beforehand, the burr area is measured. In addition, the measurement area is set on the surface of material (4 $\mathrm{mm}$ in height, $106 \mathrm{~mm}$ in width).

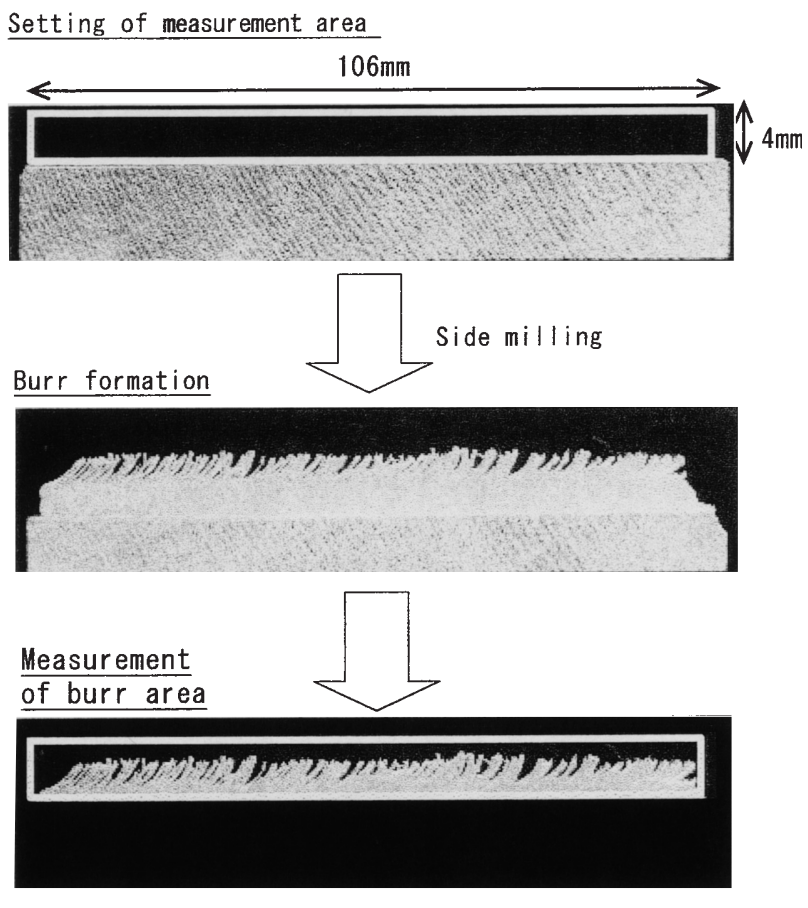

Fig. 3. Measurement method of burr area by using picture-processing device.

\section{Method of removing burr}

To remove burrs formed on the processing surface of the material after side milling, a re-milling process for the material surface was devised. That is, the center of the bit is located on the edge of processing surface, the bit point is set on the surface of the material, and the re-milling is performed as shown in Fig. 4.

In this system, there are two methods for removing the burr formed by the direction of up-milling. One method sets the feed direction of the bit in the same direction as the original side milling (type 1). The other method sets it in the opposite direction (type2). There are also two methods for removing the burr formed by 

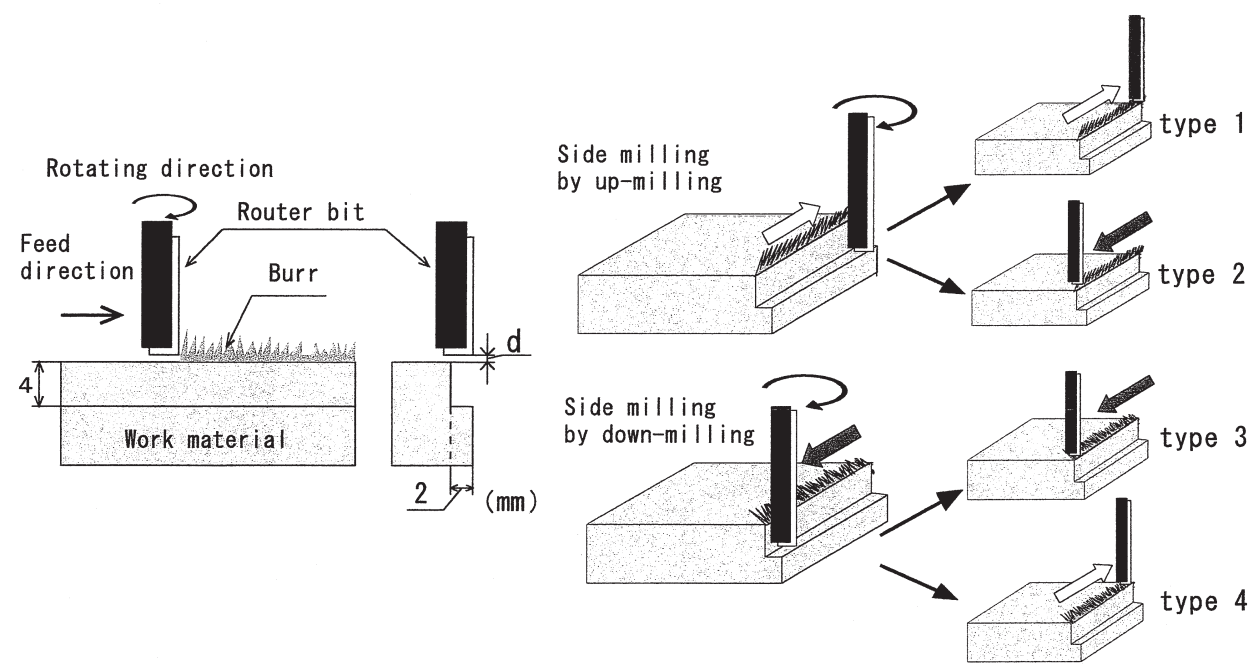

Fig. 4. Method of removing burr (type1-4).

down-milling. One sets the feed direction of the bit in the same direction as the original side milling (type3). The other sets it in the opposite direction (type4). Thus, the system adopts four methods for removing burrs. The d symbol in Fig. 4 shows the distance from the surface of the material to the bit point.

\section{VERIFICATION EXPERIMENT}

\section{Cutting tool and work material}

A throw-away type straight bit with a single-edged blade having a cutting diameter of $10 \mathrm{~mm}$ was used (Fig. 5 (A)). The shape of the tip is shown in Fig. 5 (B). The tip materials were K05-grade cemented carbide and the edge angle was 55 degrees. The rake and clearance angles in the setting were 22 and 13 degrees, respectively. A router bit in which the tool wear (edge recession) reached 40 microns by continuous cutting of particleboard was prepared. For our experiment, this worn bit was used.

Work materials used in this experiment were a medium-density fiberboard (moisture content: $8.5 \%$, specific gravity: 0.62) and air-dried spruce (moisture content: $12.6 \%$, specific gravity: 0.36). All pieces were $90 \mathrm{~mm}$ long, $90 \mathrm{~mm}$ wide, and $12 \mathrm{~mm}$ thick.

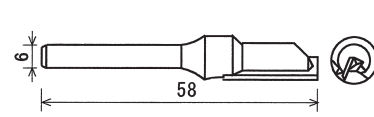

(A)

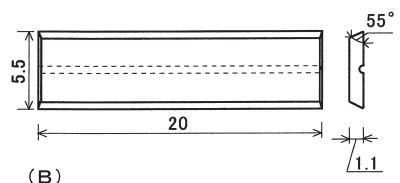

(B) of burr had been conducted in the conditions shown in Table 1. The difference between the measurement values was calculated, and divided by the value of the burr area. The calculated value was evaluated as a ratio of removal. Side milling and burr removal were repeated three times per experimental condition, and the average value was taken. The inclination angle of the grain on side milling for spruce was set at 90 degrees.

Table 1. Milling conditions in this study

\begin{tabular}{cccc}
\hline $\begin{array}{c}\text { Spindle speed } \\
(\mathrm{rps})\end{array}$ & $\begin{array}{c}\text { Knife per revolution } \\
(\mathrm{mm})\end{array}$ & $\begin{array}{c}\mathrm{d} \\
(\mathrm{mm})\end{array}$ & $\begin{array}{c}\text { Method of } \\
\text { removing }\end{array}$ \\
\hline & 0.033 & 0 & type1 \\
250 & 0.067 & 0.1 & type2 \\
& 0.100 & 0.2 & type3 \\
& 0.133 & & type4 \\
\hline
\end{tabular}

\section{RESULTS AND DISCUSSION}

Fig. 6 shows the relationships between the ratio of removal and feed per knife in MDF. From this figure, the ratio of removal was almost unaffected by feed per knife regardless of removal type (1-4), and it increased as the value of d decreased. From this result, highly accurate burr removal can be conducted by decreasing the value of $d$ when MDF is processed in this system. Moreover, adopting type 2 and 4, keeping the tool path from the side milling to the burr short and increasing the amount of feed per knife, improves the efficiency of this system.

Fig. 7 shows the relationships between the ratio of removal and feed per knife in spruce. From this figure, the ratio of removal was almost unaffected by feed per knife regardless of removal types. On the other hand, when the value of $\mathrm{d}$ is between 0 and $0.1 \mathrm{~mm}$, the ratio of removal in type1 and 2, which remove the burr after up-milling, showed higher values than that in type 3 and 4, which remove the burr after down-milling.

Figure 8 shows photos of burr formed when side 


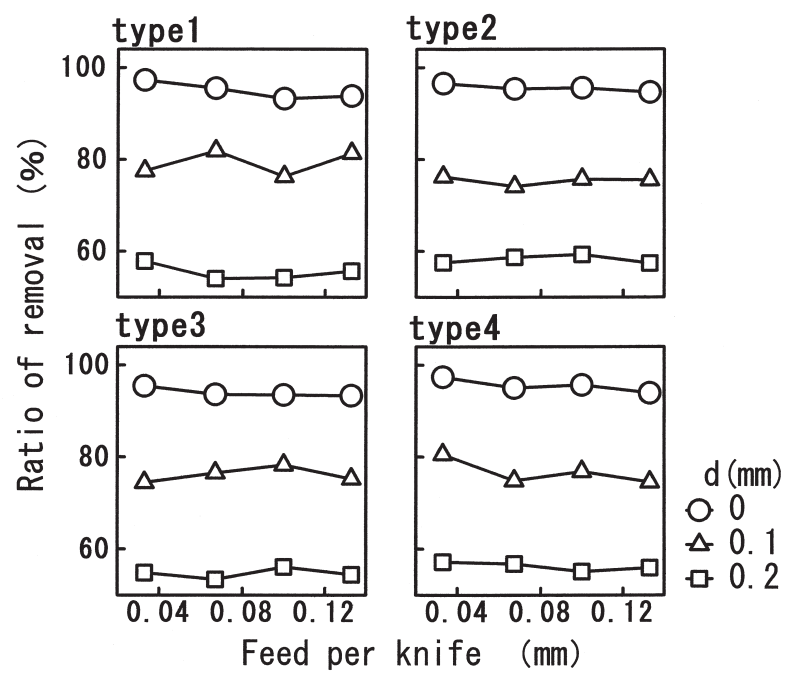

Fig. 6. Relationships between the ratio of removal and feed per knife in MDF.

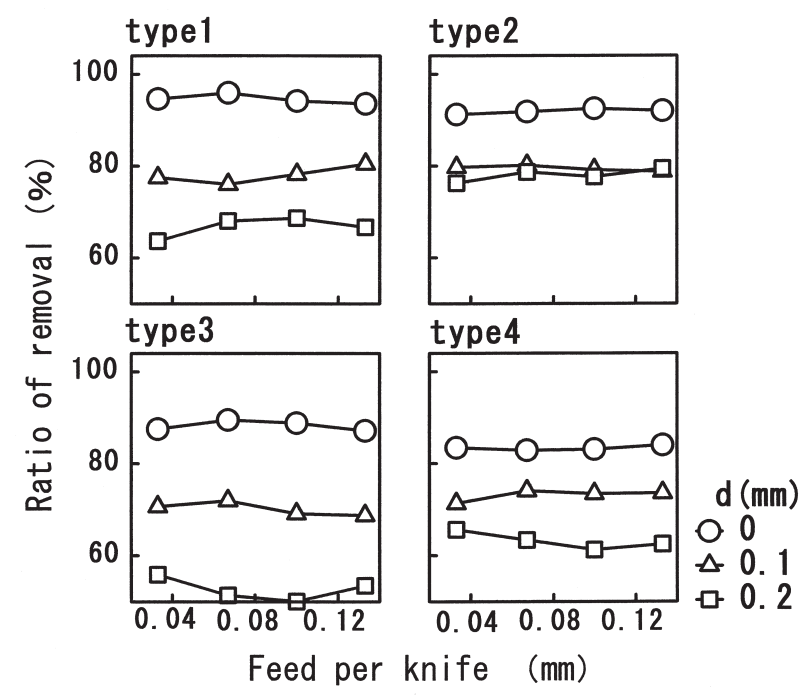

Fig. 7. Relationships between the ratio of removal and feed per knife in spruce.

milling is processed by up- and down-milling, respectively. In up-milling, the burr is formed in the vertical direction of the surface of the work material, while the curly burr is confirmed in down-milling. The decrease of the ratio of removal in type 3 and 4 is probably due to this curly burr.

Fig. 9 shows photos of burrs removed in type 2 and 4 milling. From this figure, it is confirmed that the burr falls right in type2, and falls left in type4. This is probably because the bit is put down on the burr that has not yet been removed when it passes for burr removal. In the image-processing device in which the image of the burr is input from one direction, there were differences in the ratio of removal in the four types at $0.2 \mathrm{~mm}$ of $\mathrm{d}$ because the burr which was put down as above-mentioned could not be measured accurately. Therefore, highly accurate removal during spruce processing can be conducted by decreasing the value of $\mathrm{d}$ and adopting type 1 and 2 so that the burr is removed after side milling
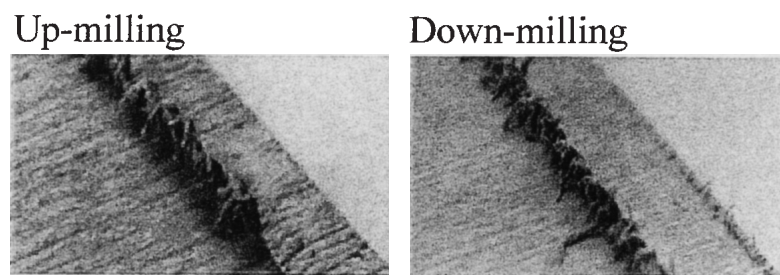

Fig. 8. Photos of burr formed after side milling (Spruce).
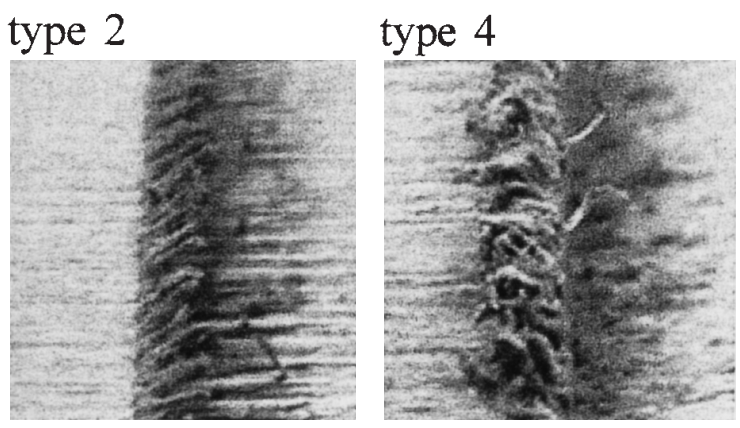

Fig. 9. Photos of burr after removing (Spruce).

by up-milling. Moreover, this system can be made more efficient by increasing the amount of feed per knife.

\section{CONCLUSIONS}

In this study, to monitor burrs formed because of tool wear, a CCD vision sensor with high reliability in monitoring was installed in a CNC router, and a system for monitoring burr formation in side milling and for removing burrs automatically was developed. In addition, verification experiments of this system were carried out.

The side milling system for monitoring burr formation was composed of an image-processing device, a control PC for the CNC router, and a monitoring PC to control some devices and collect sampling data for burr formation. From the result of the verification experiment, it was found that this system could measure the area of burrs formed in side milling and remove them automatically.

In addition, considering the ratios of removal, the recommended method of removing burrs in MDF with this system is to adopt type 2 and 4 such that the tool path is short, while that recommended for spruce is to adopt type 1 and 2 such that the burr removal is conducted after side milling by up-milling. Highly accurate burr removal can be conducted by decreasing the distance from the bit point to the surface of the work material, and the system's efficiency can be improved by increasing the amount of feed per knife.

\section{REFERENCES}

Ohuchi T, Murase Y 2001a Milling of wood and wood-based materials with a computerized numerically controlled router 
I: On the machining accuracy for grooving (in Japanese). Mokuzai Gakkaishi 47(3): 212-217

Ohuchi T, Murase Y 2001b Milling of wood and wood-based materials with a computerized numerically controlled router II: On the machining accuracy for side milling of grooves (in Japanese). Mokuzai Gakkaishi 47(6): 465-472

Ohuchi T, Murase Y 2002a Milling of wood and wood-based materials with a computerized numerically controlled Router III: Effects of tool wear on the machining accuracy and burr for grooving (in Japanese). Mokuzai Kogyo 57(7): 297-302

Ohuchi T, Murase Y 2002b A construction of tool wear monitoring system in milling of wood and wood-based materials with a computerized numerically controlled router (in
Japanese). Science bulletin of the Faculty of Agriculture, Kyushu University 56(2): 131-254

Ohuchi T, Murase Y 2005 Milling of wood and wood-based materials with a computerized numerically controlled router IV: development of automatic measurement system for cutting edge profile of throw-away type straight bit. Journal of Wood Science 51: 278-281

Ohuchi T, Murase Y 2006 Milling of wood and wood-based materials with a computerized numerically controlled router $\mathrm{V}$ : development of adaptive control grooving system corresponding to progression of tool wear. Journal of Wood Science 52: 395-400 